\title{
EPIGLOTTITIS AND PULMONARY OEDEMA IN CHILDREN
}

\author{
M.G. SOLIMAN AND P. RICHER
}

EPIglotTItis is a serious progressive disease requiring immediate treatment and close supervision to decrease morbidity and mortality. During the last four years we have treated patients with epiglottitis by nasotracheal intubation and antibiotics, following a fixed protocol. The details of the protocol and our experience with it have been published previously, ${ }^{1,2}$

In summary, once a patient with a suspected epiglottitis arrives in the emergency room, we proceed as follows:

- give humidified oxygen in semi-sitting position.

- immediately notify the anaesthetist and the otolaryngologist.

- rapid history and physical examination.

- if the clinical condition permits, X-rays of the soft tissues of the neck are done in the presence of the anaesthetist.

If the $\mathrm{X}$-ray confirms the diagnosis, we proceed with the treatment which consists of:

(a) Nasotracheal intubation under general anaesthesia.

(b) Ampicillin $200 \mathrm{mg} / \mathrm{kg} / 24$ hours and chloramphenicol $100 \mathrm{mg} / \mathrm{kg} / 24$ hours.

These are given intravenously in four divided doses. Chloramphenicol is discontinued if the antibiotic sensitivity screening shows that the causative organisms are sensitive to ampicillin.

(c) When fever and signs of toxaemia disappear, we do a laryngoscopy. If the epiglottis appears normal, the patient is extubated and observed closely for at least 24 hours.

Routine investigation includes complete blood count, urine analysis, serum electrolytes, plasma proteins, blood and throat cultures. Chest X-ray is done after intubation and after extubation of the trachea.

During the last two years, three of forty-three children with epiglottitis treated in this fashion have developed pulmonary oedema during the

M.G. Soliman, M.D., F.R.C.P.(C), Assistant Professor, P. Richer, M.D., F.R.C.P.(C), Assistant Professor, Département d'Anesthésie-Réanimation de l'Unjversité de Montréal.

Mailing address: M.G. Soliman, M.D., Département d'Anesthésie-Réanimation, Hôpital Sainte-Justine de Montréal, 3175 Chemin Côte Sainte-Catherine, Montréal, Québec H3T 1C5.

Canad. Anaesth. Soc. J., vol. 25, no. 4, July 1978 course of treatment. We present these case histories with discussion of the possible mechanisms.

\section{Case I}

A male child 19 months of age was transferred to our hospital with the diagnosis of epiglottitis confirmed by X-ray. The history indicated that the symptoms had started 16 hours previously. Physical examination showed fever, signs of upper airway obstruction and clear lungs. The history and examination were otherwise normal. Chest X-ray on admission showed normal heart and lungs (Figure 1).

The patient was transferred to the operating room and an intravenous infusion of dextrose 5 per cent in 0.2 per cent $\mathrm{NaCl}$ was started. Anaesthesia was induced and maintained with halothane in oxygen. Direct lasyngoscopy confirmed

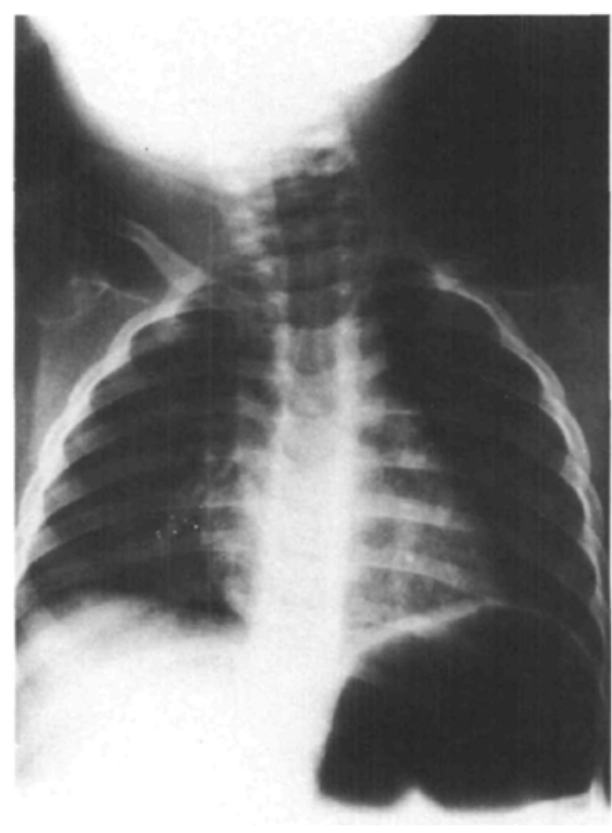

Figure 1 Case I. Chest X-ray on admission show0

Figure 1 Case l. Ches
ing normal heart and lungs. 


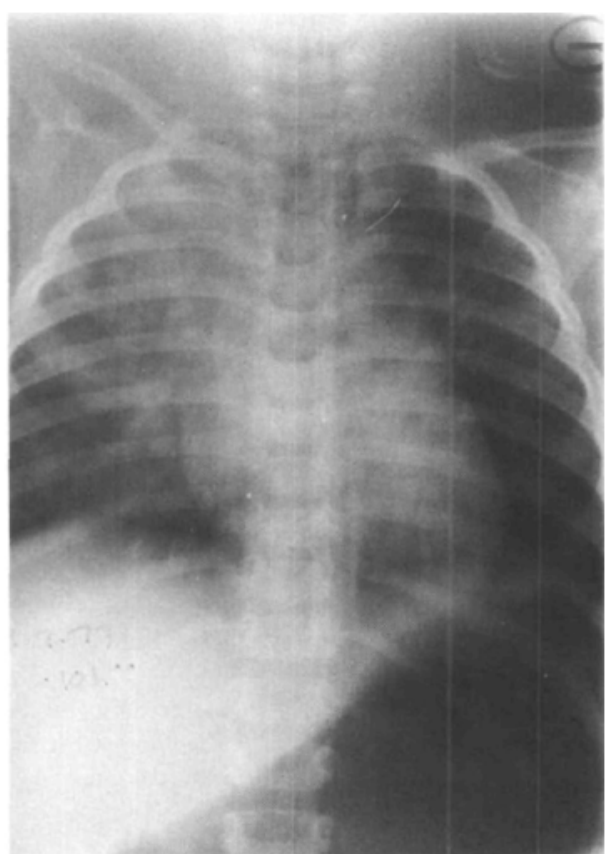

Figure 2 Case I. Chest X-ray showing pulmonary oedema after one half-hour in the intensive care unit.

the diagnosis, nasotracheal intubation was done and halothane was discontinued. Blood and throat cultures were done and the patient was transferred to the recovery room. Vital signs were normal and stable during the procedure except for rectal temperature of $38.7^{\circ} \mathrm{C}$.

In the recovery room his vital signs were stable. Chest X-ray showed normal heart and lungs and the tracheal tube in good position. Arterial blood gases revealed compensated metabolic acidosis and hypoxaemia $\left(\mathrm{Pa}_{\mathrm{O}_{2}} 7.0 \mathrm{kPa}[53\right.$ torr] with $\mathrm{FI}_{\mathrm{O}_{2}}$ 0.25). When the patient awakened he was transferred to the intensive care unit, where he received ampicillin $750 \mathrm{mg}$ intravenously. Half an hour later his clinical condition started to deteriorate. He appeared cyanosed, and dyspnoeic. Heart rate increased to $160-200 / \mathrm{min}$ and blood pressure decreased to $7.32 / 4.0 / \mathrm{kPa}(55 / 30 \mathrm{~mm}$ $\mathrm{Hg}$ ). Inspired oxygen was increased to 80 per cent. Tracheal aspiration showed presence of profuse serosanguinous secretions. Chest X-ray was compatible with pulmonary oedema (Figure 2) and $\mathrm{Pa}_{\mathrm{O}_{2}}$ was $7.71 \mathrm{kPa}$ (58 torr) with $\mathrm{Fl}_{\mathrm{O}_{2}} 0.80$.

At that time, mechanical ventilation was started using a Bennet MA I ventilator, with 80 per cent oxygen and positive end-expiratory pressure (P.E.E.P.) $\left(5 \mathrm{~cm} \mathrm{H}_{2} \mathrm{O}\right)$. There were no

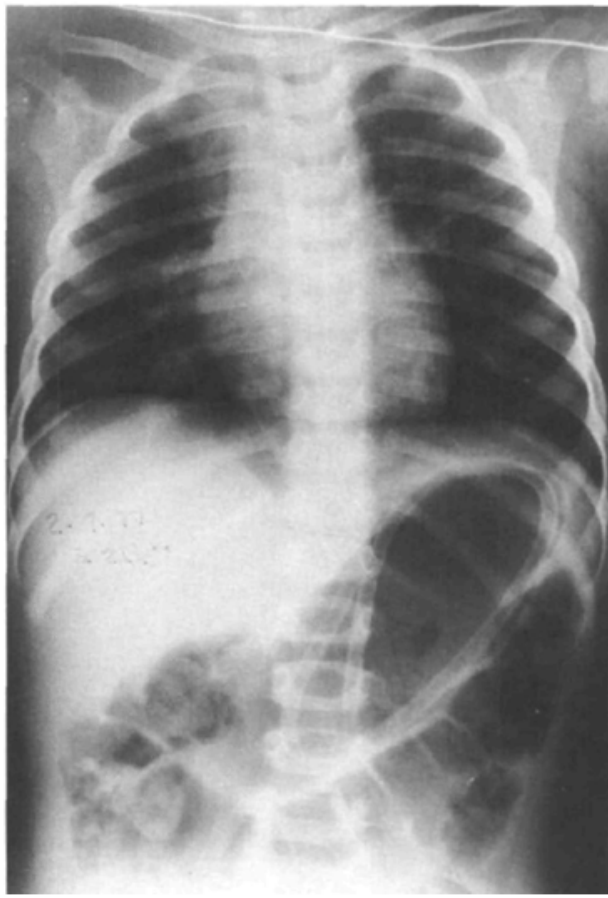

Figure 3 Case I. Chest $X$-ray showing clearing of the lungs after ten hours of mechanical ventilation with P.E.E.P. and two hours of spontaneous breathing.

signs of heart failure and total fluid intake was 180 $\mathrm{ml}$ in about three hours.

Within one hour of commencing mechanical ventilation the patient's vital signs returned towards normal. Oxygen concentration and P.E.E.P. were gradually decreased. Mechanical ventilation was stopped after ten hours. After two hours of spontaneous breathing, capillary $\mathrm{PO}_{2}$ was $7.85 \mathrm{kPa}$ (59 torr) with $\mathrm{FI}_{\mathrm{O}_{2}} 0.40$. A chest $\mathrm{X}$-ray showed clearing of both lungs (Figure 3 ). The trachea was extubated the next day. The total period of intubation was 32 hours. The patient was discharged in good condition after three days of hospitalization. Routine investigations were normal except for leucocytosis and presence of haemophylus influenzae type B in the blood.

\section{Case II}

A three-year-old male child was admitted to the emergency room because of epigastric pain, vomiting, fever, cough and progressive respiratory distress. Physical examination showed normal vital signs, except rectal temperature of $38.8^{\circ} \mathrm{C}$, excessive salivation and signs of moderate air- 


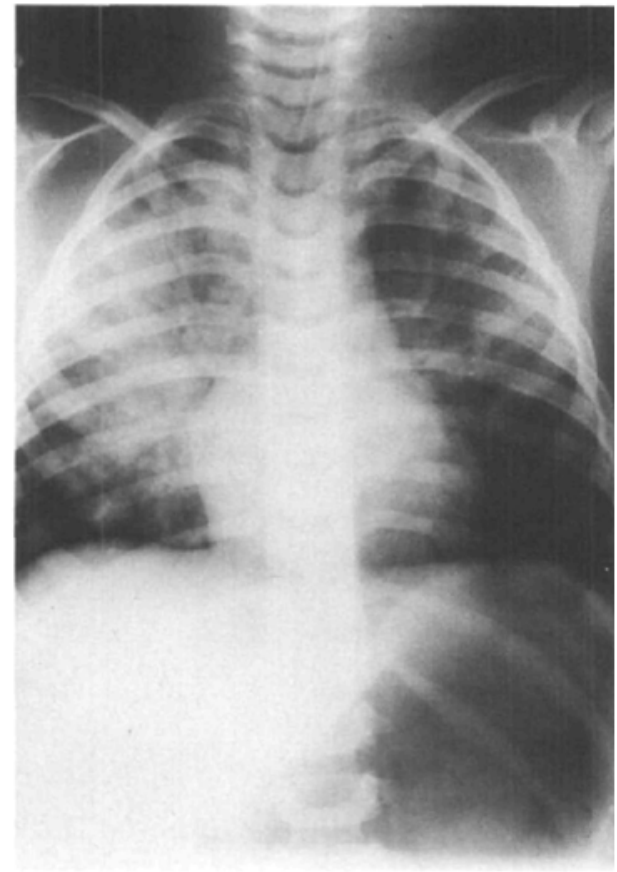

Figure 4 Case II. Chest X-ray showing pulmonary oedema 20 minutes after naso-tracheal intubation.

way obstruction. He was not cyanosed, the lungs were clear and other systems were normal. Soft tissue $X$-rays of the neck revealed an enlarged epiglottis.

The patient was transferred to the operating room, where direct laryngoscopy was done under halothane andesthesia. Laryngoscopy confirmed the diagnosis of epiglottitis. Nasotrachael intubation was done and specimens were obtained for blood culture and throat culture. There was no change in the vital signs during the procedure.

On arrival in the recovery room the rectal temperature was $38.5^{\circ} \mathrm{C}$, heart rate $122 / \mathrm{min}$, respiratory rate $32 / \mathrm{min}$, and his colour was good. Ampicillin $500 \mathrm{mg}$ was given intravenously. Twenty minutes later, he became cyanosed and dyspnoeic and the heart rate increased to $154 / \mathrm{min}$. Abundant pink secretions were aspirated from the tracheal tube. Chest $X$-ray was compatible with pulmonary oedema (Figure 4) and $\mathrm{Pa}_{\mathrm{O}_{2}}$ was $6.38 \mathrm{kPa}$ (48 torr) with $\mathrm{FI}_{\mathrm{O}_{2}} 0.75$. Total fluid given was $55 \mathrm{ml}$ of dextrose 5 per cent in 0.2 per cent $\mathrm{NaCl}$.

The lungs were ventilated mechanically by an Engstrom ventilator with 80 per cent oxygen. Thirty minutes later, he showed some clinical improvement. At this point he was extubated accidentally. The patient was taken back to the operating room where he was reintubated under general anaesthesia. In the recovery room, his vital signs were acceptable and $\mathrm{Pa}_{0_{2}}$ was $8.75 \mathrm{kPa}$ (62 torr) with $\mathrm{FI}_{\mathrm{O}_{2}} 0.80$ and spontaneous breathing. Continuous positive airway pressure (C.P.A.P.) of $5 \mathrm{~cm} \mathrm{H} \mathrm{H}_{2} \mathrm{O}$ was added, oxygen concentration was increased to 100 per cent, and the patient was left breathing spontaneously. One hour later $\mathrm{Pa}_{\mathrm{O}_{2}}$ was $37.11 \mathrm{kPa}$ (279 torr) with 100 per cent oxygen and the chest X-ray showed gradual clearing of both lungs. The patient was transferred to the intensive care unit where the $\mathrm{Fl}_{\mathrm{O}_{2}}$ and the C.P.A.P. were gradually decreased. On the next day capillary $\mathrm{PO}_{2}$ was $10.1 \mathrm{kPa}$ (76 torr) with the patient breathing room air without C.P.A.P. Chest $X$-ray showed complete clearing of both lungs (Figure 5).

The trachea was extubated after 54 hours of intubation and the child was discharged on the fifth day in satisfactory condition.

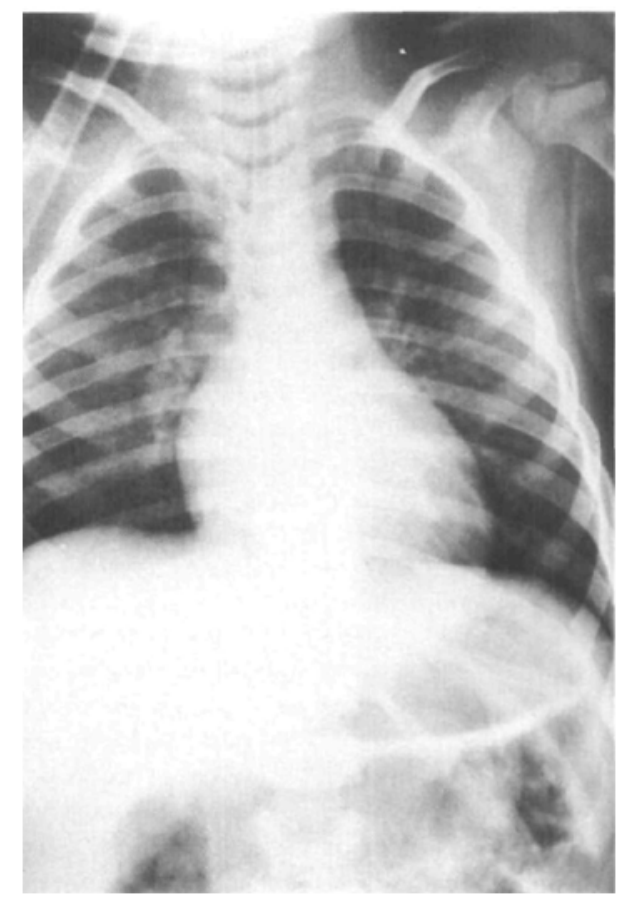

Figure 5 Case II. Chest X-ray on the day following admission showing clearing of pulmonary oedema after 30 minutes of mechanical ventilation followed by spontaneous breathing and continuous positive airway pressure. 


\section{Case III}

A two-year-old girl was admitted to another hospital because of fever, dry cough, and difficult breathing. She was treated for laryngitis (details of the treatment are not known) and because of clinical deterioration, she was transferred to our hospital.

On admission, she appeared tired and cyanosed. Rectal temperature was $38.9^{\circ} \mathrm{C}$, B.P. $12 / 8$ $\mathrm{kPa}(90 / 60 \mathrm{~mm} \mathrm{Hg})$, heart rate $138 / \mathrm{min}$ and respiratory rate $36 / \mathrm{min}$. She had signs of severe upper airway obstruction and excessive salivation. Pulmonary auscultation showed poor air entry and a few coarse rales. A diagnosis of epiglot titis was made and, due to the patient's condition, no X-rays were taken.

In the operating room, intravenous infusion of dextrose 5 per cent in 0.2 per cent $\mathrm{NaCl}$ was started, blood was taken for culture, ampicillin $500 \mathrm{mg}$ and chloramphenicol $500 \mathrm{mg}$ were given intravenously. Anaesthesia was induced and maintained with halothane in oxygen. Direct laryngoscopy confirmed the diagnosis of epiglottitis and nasotracheal intubation was done. Halothane was then discontinued and a throat culture was done. During the procedure the pa-

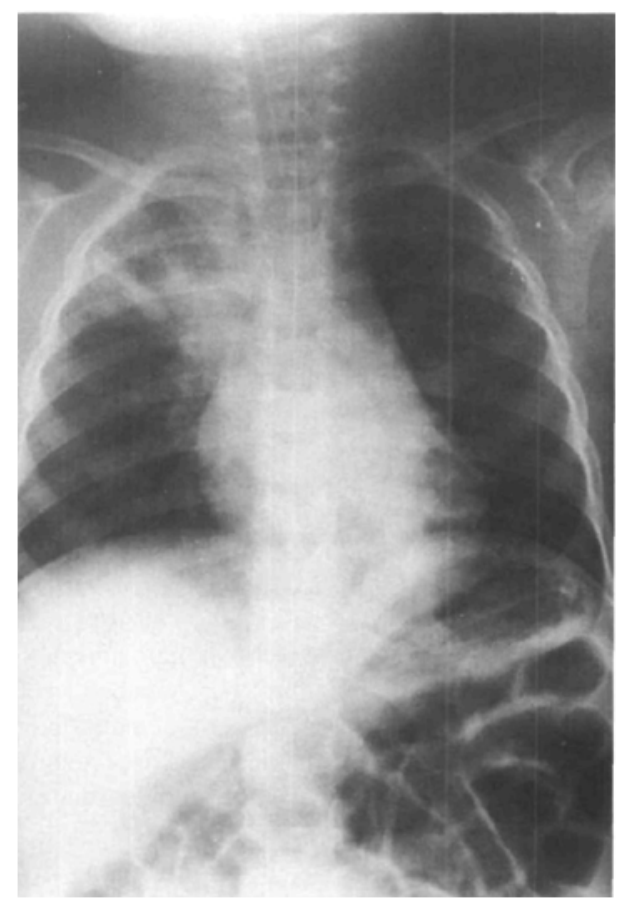

Figure 6 Case III. Chest X-ray showing pulmonary oedema.

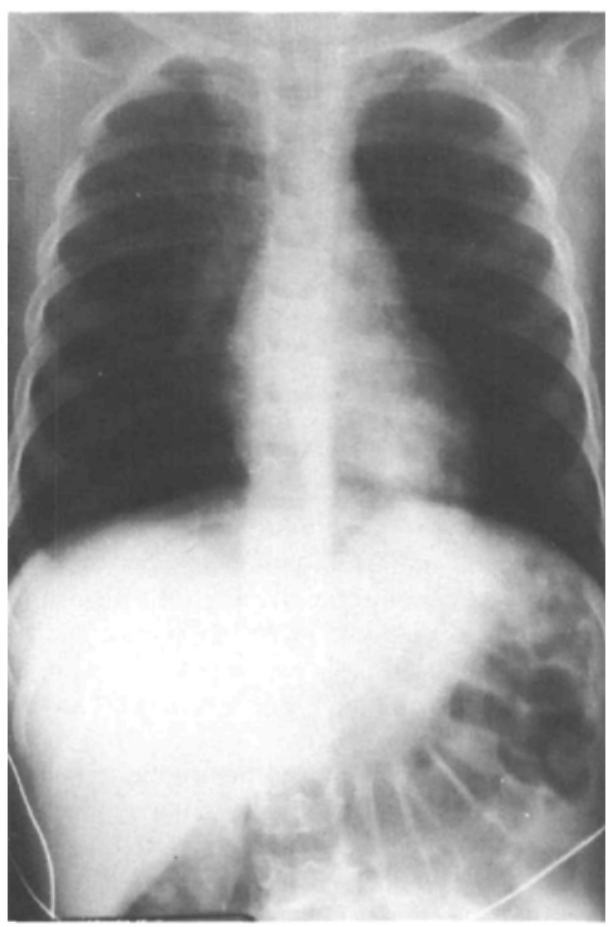

Figure 7 Case III. Chest X-ray showing dramatic clearing of pulmonary oedema following two hours of mechanical ventilation with P.E.E.P.

tient received $75 \mathrm{ml}$ of fluid intravenously and the cardiovascular parameters were stable.

A few minutes after arrival in the recovery room her condition deteriorated. Rectal temperature was $41.5^{\circ} \mathrm{C}$, heart rate $200 / \mathrm{min}$, respiratory rate $60-80 / \mathrm{min}$ and B.P. $8.0 / 5.3 \mathrm{kP}(60 / 40 \mathrm{~mm}$ $\mathrm{Hg}$.). She had cold cyanosed hands and feet. Rales and crepitations were present in both lungs. The chest $X$-ray was compatible with pulmonary oedema (Figure 6). $\mathrm{Pa}_{\mathrm{O}_{2}}$ was $5.32 \mathrm{kPa}$ (40 torr) $\left(\mathrm{FI}_{\mathrm{O}_{2}}>0.9\right)$. The lungs were ventilated mechanically using a Bennet MA I with 100 per cent oxygen and P.E.E.P. of $3 \mathrm{~cm} \mathrm{H} \mathrm{H}_{2} \mathrm{O}$. She was given morphine sulphate $2 \mathrm{mg}$ intravenously and cooled with a cooling mattress and application of alcohol to the skin.

One hour later, her vital signs were improved and $\mathrm{Pa}_{\mathrm{O}_{2}}$ was $34.31 \mathrm{kPa}$ (258 torr) with $100 \mathrm{per}$ cent oxygen. $\mathrm{FI}_{\mathrm{O}_{2}}$ was gradually decreased. Two hours later, the chest X-rays showed a dramatic change with clearing of most of both lungs (Figure 7).

The patient was transferred to the I.C.U. where mechanical ventilation was discontinued after six hours. The $\mathrm{FI}_{\mathbf{O}_{2}}$ was decreased to 0.40 . 
The next day, the patient was in satisfactory condition. The $\mathrm{Pa}_{\mathrm{O}_{2}}$ was $22 \mathrm{kPa}$ (165 torr) with 30 per cent oxygen and spontaneous breathing. Other laboratory tests were normal except for leucocytosis. The Blood culture grew haemophylus infiuenzae type $B$. The total period of intubation was 42 hours and she was discharged in good condition on the fourth day.

\section{DisCUSSION}

Epiglottitis is usually looked upon as upper airway obstruction and relief of this obstruction by nasotracheal intubation and antibiotic therapy eliminates most of the morbidity and mortality. This report shows that pulmonary oedema is a relatively frequent complication of epiglottitis. However, it usually has a benign course and re. sponds rapidly to simple measures such as mechanical ventilation and increased airway pressure.

Although it is difficult to determine the exact mechanism for the development of pulmonary oedema in these cases, we can postulate several mechanisms, which may work separately or concurrently to produce pulmonary oedema.

The first possibility is that pulmonary oedema develops secondary to changes in the physical factor's, controlling the movement of fluids across the capillary alveolar membrane,,$^{3,4}$ a summary of which appears in Figure 8.

Upper airway obstruction is associated with increased negative intra-alveolar pressure and hypoxia. Several studies have shown that hypoxia produces increased capillary permeability and pulmonary vasoconstriction. Hypoxia also produces massive sympathetic discharge ${ }^{5-8}$ with systemic vasoconstriction and translocation of the blood from the systemic circulation to the pulmonary circulation.

The association of pulmonary hypervolaemia and vasoconstriction leads to an increase in the pulmonary capillary filtration pressure. This, in addition to the increased capillary permeability and the negative intra-alveolar pressure, will cause a shift of the fluids across the capillaryalveolar membrane from the intravascular compartment to the intra-alveolar compartment.

Although it is easy to explain the development of pulmonary oedema, on the basis of physical changes, this is probably not the only mechanism. If it were, we would expect pulmonary oedema to occur before intubation when the airway obstruction and hypoxia are greatest. This was not the case in two of our patients.

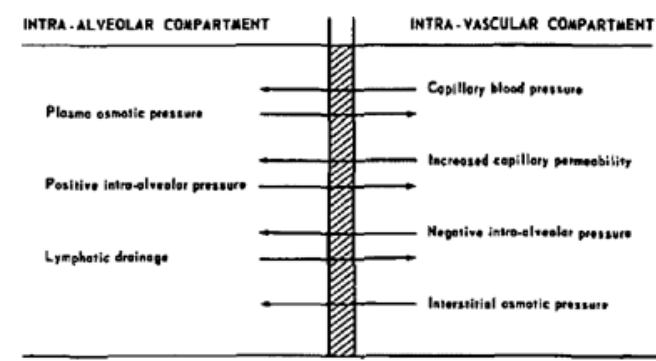

FIGURE 8 Representation of physical factors controlling the movement of fluids across the capillary alveolar membranes.

A second possibility is that pulmonary oedema develops secondary to bacteraemia and endotoxinaemia. Several studies and reports ${ }^{9-15}$ have shown that bacteraemia and endotoxinaemia may be associated with pulmonary oedema.

In these cases there was bacteraemia of haemophylus influenzae type $B$. They also underwent manipulation and instrumentation of the infected region, a factor which increases the bacteraemia. ${ }^{16.17}$ In addition, these patients received high doses of a bacteriocidal agent (ampicillin), ${ }^{18.19}$ capable of liberating the endotoxins and the bacterial membrane components. ${ }^{9,15.20}$

The time of onset of the pulmonary oedema and its association with symptoms and signs similar to those of septic shock support this possibility. A recent report suggested that the endotoxins and the bacterial membrane components are removed by the reticuloendothelial system, ${ }^{21}$ This may explain the transitory course of the pulmonary oedema in these patients.

A third possible explanation is that pulmonary oedema develops secondary to myocardial depression by the antibiotics ${ }^{22,23}$ and the anaesthetic agents. Although this seems unlikely it cannot be excluded. None of our patients showed signs of heart failure and two of them received the antibiotics 45 and 120 minutes after halothane was discontinued. In addition, Travis, et al. ${ }^{24}$ measured the pulmonary capillary wedge pressure in a similar case and found it to be normal.

Although we cannot point to one mechanism as responsible for the development of pulmonary oedema in these cases, a combination of several factors seems the most probable explanation.

\section{SUMMARY}

We have presented three patients with epiglottitis who developed pulmonary oedema during 
the course of treatment with nasotracheal intubation and antibiotics.

The exact mechanism for the development of pulmonary oedema in these patients is not known. Possible mechnisms are change in the physical factors controlling the movement of fluids across the capillary-alveolar membrane, transitory bacteraemia and endotoxinaemia, or myocardial depression by the antibiotics and the anaesthetic agent.

The pulmonary oedema had a benign course and responded to mechanical ventilation and increased airway pressure.

\section{RÉSUMÉ}

L'épiglottite est une maladie infectieuse, à progression rapide, nécessitant un traitement immédiat et une surveillance étroite afin de réduire sa morbidité et sa mortalité. Depuis quatre ans, notre approche consiste à soulager l'obstruction par une intubation nasotrachéale et à traiter avec des antibiotiques à haute dose.

Nous avons observé l'apparition d'un œedème aigu du poumon chez trois patients au cours du traitement de quarante-trois cas d'épiglottites. L'épisode aigu répond à la thérapeutique habituelle et évolue favorablement.

L'odème pulmonaire chez ces patients pourrait être attribuable à plusieurs facteurs: changement des facteurs physiques qui contrôlent le passage des liquides à travers la membrane alvéolo-capillaire; présence d'une bactériémie et d'une endotoxémie transitoires ou l'effet dépresseur sur le myocarde d'agents anesthésiques et antibiotiques.

\section{REFERENCES}

1. Weber, M.L., Desjardins, R., Perreault, G. RIVARD, ., TURMEL, Y. Acute epiglottitis in children: treatment with nasotracheal intubation, report of fourteen consecutive cases. Pediatrics 57 : $152(1976)$.

2. Blanc, V.F., Weber, M.L., Leduc, C., Laberge, R., Desjardins, R., \& Perrault, G. Acute epiglottitis in children: management of twenty-seven consecutive cases with nasotrachael intubation, with special emphasis on anaesthetic consideration. Canad. Anaesth. Soc. J. 24: 1 (1977).

3. Robin, E.D., Cross, C.E., \& Zelis, R. Pulmonary edema. N. Engl. J. Med. 288:239-292 (1973).

4. Stalars, S.A. \& Mellins, R.B. Mechanical forces producing pulmonary edema in acute asthma. N. Engl. J. Med. 297: 592 (1977).

5. Fritts, H.W., Odell, J.e., harris, P., Braun-
WALD, E.W., \& Fishman, A.P. Effect of acuie hypoxia on the volume of blood in the thorax. $\mathrm{Cir}$ culation $22: 216(1960)$.

6. WEST, J.B. Distribution of the blood flow in isolated lung: relation to vascular and alveolor pressure. J. Appl. Physiol, 19:713 (1964).

7. Theodore, J. \& Robin, E.D. Pathogenesis of neurogenic pulmonary edema. Lancet 2: 749 (1975).

8. Kleiner, J.P. \& Nelson, W.P. High altitude pulmonary edema; a rare disease. J.A.M.A. 234: 49l (1975).

9. HASSEN, A. Gram negative bacteremic shock. Medical clinic of North America 57: 1403 (1973).

10. STODDART, J.C. \& WARDLE, E.N. Post-traumatic respiratory distress due to endotoxinemia and intravascular coagulation. British Joumal of Anaesthesia 46: 894 (1974).

11. Milligan, G.F., MacDonald, J.A.E., Mellon, A., \& Ledingham, I.MCA. Pulmonary and hematologic disturbances during septic shock. Surgery, Gynecology and Obstetric 138: 43 (1974).

12. WILSON, J.W. Pulmonary factors produced by septic shock: cause of consequence of shock lung. J. of Reproductive Medicine 8: 307 (1972).

13. Parratt, J.R. Myocardial and circulatory effects of E. Coli endotoxins. British J. of Pharmacology 47: 12 (1973).

14. Hinshow, L.B., ARcher, L.T., Greenfield, L.T. Miller, J.A., \& Guenter, C.A. Effect of endotoxins on myocardial performance. J. of Trauma 12: 1056 (1972).

15. Hershey, S.G., DE LA Guerco, L.R.M., \& Meconn, J.R., Ed. Septic shock in man. Boston, Little Brown (1971).

16. Berry, F.A., Blankenbaker, W.L., and Bal.l, C.G. A comparison of bacteremia occurring with nasotracheal and orotracheal intubation. Anaesth. Analg. (Cleve) $52: 873$ (1973).

17. Baltch, A., Buhac, I., Agrawal, A., O'ConNor, P., Bram, M., \& Malatino, E. Bacteremia after upper G.I. endoscopy. Arch. Intern. Med. 137: 594 (1977).

18. Goodman, L.S. \& Gilman, A. The pharmacological basis of therapeutic. The Macmillan Company (1970).

19. ToP, SR. H. \& Wehrle, P.F. Communicable and infectious diseases. The C.U. Mosby Company, Saint Louis, p. 38 (1976).

20. HopkIN, D.A. Letter antibiotics and endotoxics shock. Br. Med. J. 4: 1112 (1973).

21. FINE, J. Endotoxins and the reticulo-endothelial system in shock. In conference on the dynamics of septic shock in man. S.G. Hershey, et al. Little, Brown and Co., Boston, p. 103 (1968).

22. Young-ZiN, S. \& KATZ, R.L. Interaction of halothane and antibiotics on isometric contraction on rat-heart muscle. Anaes. and Analg. 56:515 (1977).

23. Cohen, L.S., Wechsler, A.S., Mitchell, J.H., \& GLIck, G. Depression of cardiac function by streptomycin and other antimicrobial agents. Am. J. Cardiol. 26: 505.

24. Travis, K.W., Todres, D., \& Shannon, D.C. Pulmonary oedema associated with croup and epiglottitis. Pediatrics 59: 695 (1977). 